\title{
EFEITOS DA UREIA APLICADA NO SOLO E NA FOLHA, NA PRODUÇÃO E QUALIDADE DO TRIGO EM GRÃO (Triticum aestivum L.)*
}

\author{
A.M.L. Néptune ** \\ R.S. Lourenço ***
}

RESUMO

O presente trabalho teve como objetivo estudar a influência da adubação nitrogenada na cultura do trigo (Triticum aestivum L.) em condições de campo.

O ensaio foi realizado no ano de 1971 na Estação Experimental de "Vila Velha, da Secretaria da Agricultura do Estado do Paraná localizada no município de Ponta Grossa-PR.

Foram utilizados três níveis de nitrogênio, 0,60 e $90 \mathrm{~kg}$ $\mathrm{N} / \mathrm{ha}$, sobre uma adubação fundamental de $120 \mathrm{~kg} \mathrm{P}_{2} \mathrm{O}_{5} / \mathrm{ha}$ na forma de superfosfato simples com $21 \%$ de $\mathrm{P}_{2} \mathrm{O}_{5}$ e $60 \mathrm{~kg}$ $\mathrm{K}_{2} \mathrm{O} / \mathrm{ha}$ como cloreto de potássio com $60 \%$ de $\mathrm{K}_{2} \mathrm{O}$.

$\mathrm{O}$ adubo nitrogenado foi a uréia com $45 \%$ de $\mathrm{N}$, aplicada em forma sólida no sulco de plantio e em cobertura, na forma sólida e como solução aquosá a $2 \%$ em pulverização foliar, no perfilhamento e emborrachamento.

Os resultados obtidos permitiram verificar um aumento na produção de grãos em função da adubação nitrogenada sendo que não se verificaram diferenças significativas para parcelamento ou época de aplicação, formas e doses de nitrogênio.

Considerando a produção de proteína, com base no $\mathrm{N}$ total, foram significativas as diferenças em favor das doses de $90 \mathrm{kgN} / \mathrm{ha}$. Para as aplicações do adubo na forma sólida obtiveram-se melhores resultados quando do parcelamento ou aplicações mais tardias. Estas variações não se verificaram para as coberturas em pulverização foliar. As formas de aplicações foram equivalentes.

A aplicação de nitrogênio parece ter diminuido o teor de lisina e, também, aumentado o teor de gluten do grão do trigo, quando comparados com a testemunha.

* Recebido para publicação em 30 de Dezembro de 1977.

* Centro de Energia Nuclear na Agricultura e Departamento de Solos, Geologia e Fertilizantes, Escola Superior de Agricultura "Luiz de Queiroz" - Universidade de São Paulo.

*** Faculdade de Agronomia de Curitiba, Universidade Federal do Puraná. 


\section{INTRODUÇÃO}

O nitrogênio é constituinte estrutural das proteínas e um dos principais fatores no rendimento do trigo.

A pesquisa de efeito de fontes de nitrogênio na produção do trigo, em nossas condições, tem demonstrado que o cereal responde positivamente à aplicação de uréia. Pelo seu alto teor de nitrogênio e em virtude de estar sendo produzida no país, a ur-ia deve se constituir, no futuro, na principal fonte do nutriente para a cuitura. A aplicação de uréia, em soluçã̃o ou juntamente com os defensivos, vem sendo utilizada.

O objetivo do presente trabalho foi verificar o efeito de dose, época e forma de aplicação da uréia no rendimento e qualidade da produção de trigo.

\section{REVISÃO BIBLIOGRÁFICA}

Efeito do parcelamento e época de aplicação do nitrogênio

Trabalho de RANKIN (1946), sugere que as aplicações parceladas de nitrogênio, evitando a perda do elemento por lavagem, garantem uma boa produção de grãos.

PATELLA (1969), HUCKLESBY et al. (1971), obtiveram evidencias de que o parcelamento das doses de nitrogênio, favoreceram o rendimento do trigo.

Outros pesquisadores, no entanto, obtiveram melhores resultados, quanto à produção de grãos, para as adubações nitrogenadas feitas sómente no plantio (WAHHAB e HUSSAIN, 1957).

Vários pesquisadores, (RAN̂KIÑ, 1946; ;FINNEY et al., 1957; WAHHAB e USSEIN, 1957; SADAPHAL e DAS, 1966; HAMID, 1972), tem demonstrado o efeito positvio do parcelamento do nitrogênio, no peso de 1.000 sementes.

O parcelamento das doses de nitrogênio, parece assumir seu mais importante papel no aumento do teor de proteína nos grãos de trigo. MC NEAI e DAVIS (1954), observaram que a aplicação de mais de 100 $\mathrm{kg} / \mathrm{ha}$, sómente na semadura, aumentou a produção, mas, não o teor de proteína consistentemente, e concluem: "Esses dados confirmam o bem conhecido princípio de que a utilização mais tardia no nitrogênio é essencial para o máximo conteúdo de proteína".

DAVIDSON e LE CLERC (1923), citados por MC CALLA (1933), encontraram que aplicando nitrato nos primeiros estágios de crescimen- 
to do trigo, aumentava a produção de grão e havia um pequeno aumento no teor de proteína do grão.

Pesquisas realizadas por FINNEY e outros (1957), MORRIS e JACKSON (1959), SADAPHAL e DAS (1966) e NEPTUUNE e PATELLA $1970)$, tamb $\mathrm{m}$ confirmam o aumento do teor de proteína com o parcelamento da uréia em trigo e outras culturas.

Efeito de doses de nitrogênio

Sabe-se que a resposta ảo trigo às diferentes doses de nitrogênio, no que diz respeito à produção de grãos, é uma função dos efeitos genéticos e ambientais no metabolismo de cada variedade.

$\mathrm{Na}$ India, México e Paquistão, países onde se procesou a "revolução verde" as variedades de trigo receberam até $160 \mathrm{kgN} / \mathrm{ha}$ e, algumas delas responderam positvamente. O nível de recomendação permanecu ao redor de $120 \mathrm{kgN} /$ ha (BOURLAUG, 1969).

Para as variedades brasileiras atuais, de porte alto e palhudas, o nitrogênio pode produzir acabamento e aceita-se que doses elevadas retara'am a maturação além de aumentar a susceptibilidade às doenças (KAIJCKMANN, 1965). Os resultados da pesquisa, permitem afirmar que as variedades existentes em nosso meio não apresentam condições para respostas econômicas e doses maiorse do que $60 \mathrm{kgN} / \mathrm{ha}$ (PAN, 1968; PATELLA, 1969 e RAMOS, 1970).

HUNTER (1958) não encontrou aumento no conteúdo de proteínas quan'o doses de nitrogênio foram aplicadas além daquela necessária para fornecer a "produúção máxima".

E farta a literatura na indicação de que a adubação nitrogenada aumenta o teor de proteina nos grãos do trigo e disto encontramos provas nos trabalhos de FINNEY e outros (1957), PUENTE (1958), HUNTER, (1958), RAMON e LAIRD (1959), LITTLER 1962), MATHUR et al. (1969), SRIVASTAVA et al. (1970) e HUCKLESBY et al. (1971). Entretanto, observa-se que o aumento no teor de proteína, não raramente, é acompanhado pela não melhora ou diminuição da qualidade das proteínas. Evidenciam esse fato trabalhos como os de FINNEY e outros (1957), LITTLER (1962), SRIVASTAVA et al (1970) e HUCKLESBY et al. (1971).

A qualidade das proteínas vegetais é determinada pelo conteúdo de certos aminoácidos essenciais como lisina, triptofano, metionina HERA, 1970). KAUL (1973) observa que os dois primeiros aminoácidos lirn itantes em trigo são lisina e iso-leucina, respectivamente. 
SRIVASTAVA et al. (1970), afirma que um moderado aumento de proteína do grão é desejável para se obter alta concentração de lisina, e cita LARSEN e NIELSEN (1966), os quais acham que a adubação nitrogenada diminui a lisina, a treonina, a valina e aumenta o ácido g’utâmico, a prolina e a fenilalanina no trigo. SRIVASTAVA ế al. (1970) - no mesmo trabalho citam ainda POZSAR e KISS (1865), os quais referem-se a um aumento na proporção de lisina, arginina e histidina, acompanhado por uma diminuição em ácido glutâmico, leucina e treonina, sob condições de altos níveis de fertilização.

BHAID et al. (1969) citado por SRIVASTAVA et al. (1970), achagrão do trigo em $37 \%$. Entretanto, este aumento foi acompanhado por um decréscimo na concentração de lisina e triptofano.

VLASYUK e RUDENKO (1969), conduzindo ensaios para observar influências de doses de fertilzantes na qualidade de panificação do trigo, encontraram efeito positivo no aumento do teor de gluten quancio elevaram as doses de nitrogênio.

COIC (1957), refere-se à qualidade do pão como sendo esta depen-dente do teor e qualidade do gluten e indica que a qualidade do gluten é dependente da variedade.

Efeito de Formas de Aplicação de Nitrogênio

Desde 1914, a literatura se refere à pulverização foliar cie fertilizante nitrogenado (BALI_ARD and VOLCK, 1914; LEWIS and ALIEN, 1914) e o ritrogênio é ainda o nutriente mais aplicado por este métocio. A uréia é a mais usual forma de nitrogênio usada em pulverização pela sua grande solubilicade e seu alto conteúdo de $\mathrm{N}$, o que permite a anlicacão de boa quantidade deste nutriente em soluções diluídas (rHoRNE, 1955 ).

O nitrogênio da uréia é absorvido, transportado e metabolizado mais rapidamente do que gualquer outro nutriente em pulverização (WITTWER e TEUBNER, 1959). Afirmam os mesmos autores, que a absorção da uréia pulverizacia é mais rápida à noite e durante as primeiras horas da manhã, evidencianco uma marcada influência da umidade relativa. Relatam, ainda, que os dados relativos aos efeitos da temperatura e luminosidade na absorção, não são conclusivos.

Segundo THORNE (1955), a pulverização foliar é vantajosa sobre a adubação no solo quando:

- os nutrientes aplicados no solo, pelas condições do mesmo, cu competição do mato, não são absorvidos;

- um período curto é requerido para as respostas;

- pode-se conciliar às práticas de rotina tais como aplicação de inseti- 
cidas, fungicidas e/ou herbicidas;

- das aplicações tardias por aviões;

- do estudo teórico de nutrição de plantas.

Resultados preliminares de ensaio relatados por GARDNER (1955), sugerem não haver vantagens, em termos de peso de matéria seca e proteína, com base no $\mathrm{N}$ total, para o nitrogênio pulverizado com uréia, em vez da aplicação em cobertura na forma sólida.

Experimentos para comparar a eficiência da forma de aplicação da uréia no trigo, mostraram resultados semelhantes com relação ao aumento dos teores de nitrogênio no grão e na palha. Uma parcial substituição do nitrogênio no solo por pulverização não afetou o número de perfilhos, o número de espigas ou de grãos por espiga, e a produção permaneceu inalterada para os níveis testados (MATHUR et al., 1969) .

Em ensaio em vasos, o efeito da aplicação foliar e ao solo, com nitarato de amônio, uma semana antes do emborrachamento, foi estudado sob três diferentes regimes de umidade. $\mathrm{O}$ efeito do $\mathrm{N}$ aplicado nas folhas foi imediato, mas, relativamente de curta duração e só aumentou a produção das plantas em virtude do aumento do peso da espiga principal. $\mathrm{O}$ efeito do $\mathrm{N}$ aplicado ao solo foi retardado, porém mais efetivo. ocasionando um aumento na colheita devido ao maior número do perfilhos. A aplicação de $\mathrm{N}$ ao solo foi mais eficiente do que a aplicação foliar (NERSON e KARCHI. 1972).

SRIVASTAVA et al. (1970), estudaram o efeito da aplicação da uréia, foliar e no solo, na composição de aminoácidos e proteína do trigo, com irigação e em condições de campo.,A aplicação no solo aumentou ligeiramente a concentração de proteína sendo que o aumento máximo foi de $11 \%$. As concentrações de lisina e triptofano também aumentaram significativamente. Com a aplicação foliar, aumentou o conteúdo de proteína cerca de $20 \%$, mas, caiu o teor de lisina. A concentração de aminoácidos essenciais como ácido aspártico, ácido glutâmico e prolina, foi maior. Houve ligeira diminuição nos amnoácidos básicos.

\section{MATERIAL E METODOS}

Trabalho de Campo

Local

O ensaio foi instalado na Estação Experimental de Vila Velha, da Secretaria da Agricultura do Estado do Paraná, Município de Ponta Grossa-PR, situada a $25^{\circ} 25^{\prime}$ de Latitude Sul e $49^{\circ} 09^{\prime}$ 'W. Grnv. a $880 \mathrm{~m}$ de altitude.

Solo 
O experimento foi instalado e conduzido em um Latossol Vermelho Escuro-orto. Esta unidade apresenta perfis profundos $(2$ a $3 \mathrm{~m}$ ) e com boa profundidade efetiva, não raro, superior a $2 \mathrm{~m}$. E formada sobre folhelho argiloso e apresenta relêvo de suave ondulado a ondulado.

Os resultados das análises químicas, para o local do experimento, são apresentados no quadro abaixo:

\begin{tabular}{ccccccc}
\hline $\begin{array}{c}\mathrm{pH} \\
\left(\mathrm{em} \mathrm{H} \mathrm{H}_{2} \mathrm{O}\right)\end{array}$ & $\begin{array}{c}\% \mathrm{~N} \\
\text { total }\end{array}$ & $\% \mathrm{M} . \mathrm{O}$. & $\mathrm{PO}_{4}^{3}-$ & $\mathrm{K}+$ & $\mathrm{Ca}^{2+}$ & $\mathrm{Mg}^{2+}$ \\
\hline 4,9 & 0,13 & 4,47 & 0,02 & 0,08 & 2,10 & 0,40 \\
\hline
\end{tabular}

$\mathrm{O}$ pH fgi determinado utilizando-se a relação solo-água igual a 1:2,5. O carbono orgânico foi determinado pelo método de Walkley-Black, descrito por JACKSON (1958), e, para obter a porcentagem de matéria orgânica multiplicou-se a porcentagem de carbono orgânico por 1,724. O nitrogênio total foi determinado pelo método de Kjeldahl, descrito por JACKSON (1958). O fósforo solúvel e o potássio trocável, pelo método descrito por CATANI et al. (1955) e o cálcio e o magnésio por absorção atômica no espectrofotômetro EEL (Evans Electroselenium Ltc.), em extrato obtido segundo GLORIIA et al. (1965).

\section{Dados Meteorológicos}

As condições meteorológicas verificadas no local, no período abrangido pela cultura, conforme dados anotados e fornecidos pela Secretaria de Agricultura do Estado do Paraná e o balanço hídrico calculado à partir desses dados, segundo THORNTHWAITE e MATHER, (1955) citado por VILLA NOVA et al. (1968). O curso da precipitação, evapotranspiração potencial e real e disponibilidade normais de ágíua no solo, segundo o balanço hídrico, foi estabelecido. (Quadro 1).

\section{Delineamento experimental}

O ensaio constou de 15 tratamentos com quatro repetições em blocos ao acaso. 


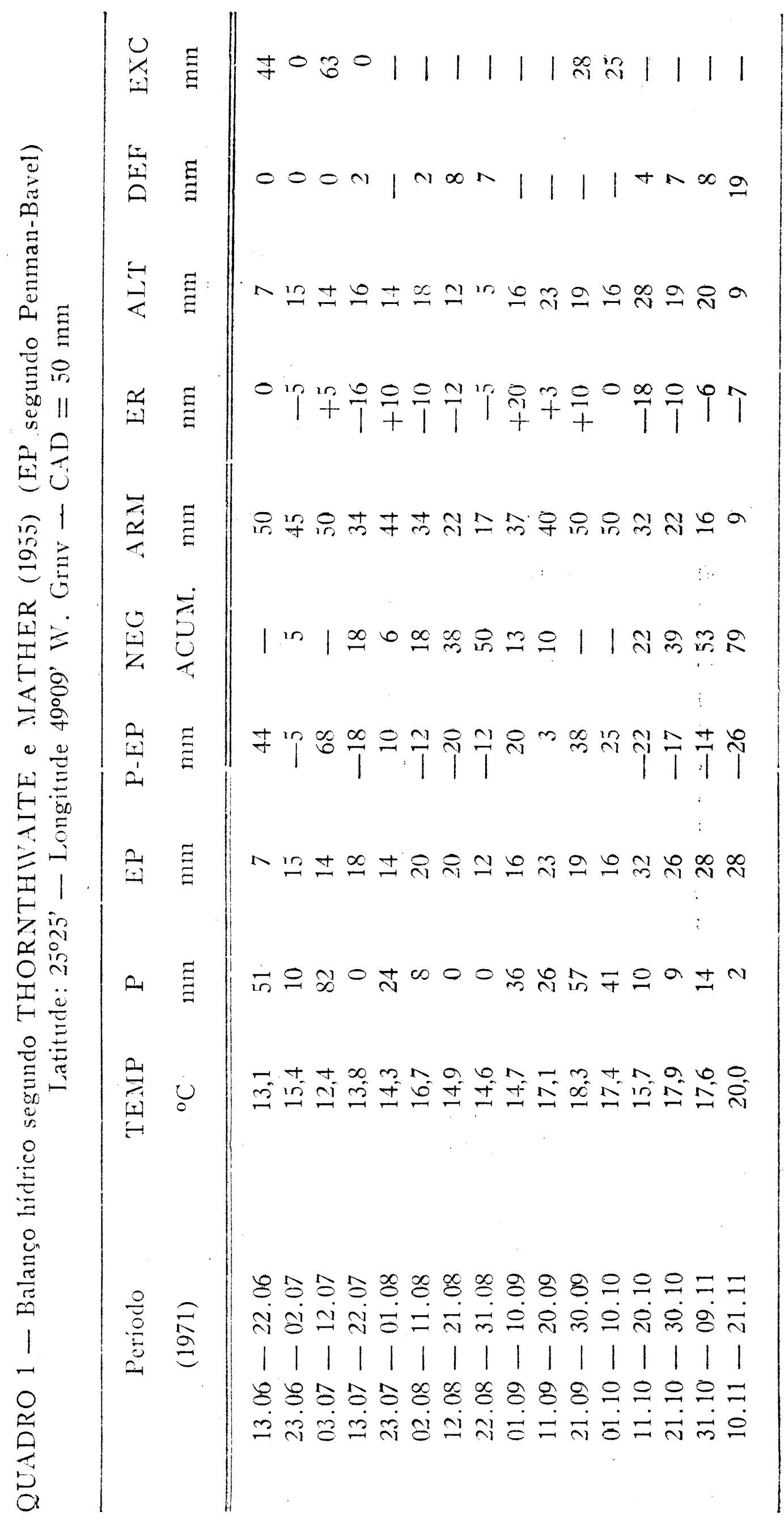


Os tratamentos foram: três níveis de nitrogênio $(0,60$ e 90 $\mathrm{kgN} / \mathrm{ha}$ ), aplicados em três fases da cultura (semeadura, perfilhamento e emborrachamento) e em duas formas, uréia sólida e uréia em solução aquosa a $2 \%$, em pulverização foliar, segundo esquema do Quadro 2. Todas as aplicações no plantio foram na forma sólida e nosulco.

QUADRO 2 - Doses de $\mathrm{N}$ em $\mathrm{kg} / \mathrm{ha}$, aplicadas no plantio, perfilhamento e emborrachamento, sob as formas sólida e líquida

\begin{tabular}{|c|c|c|c|c|c|c|}
\hline \multirow{2}{*}{$\begin{array}{l}\text { Trata- } \\
\text { mento }\end{array}$} & \multicolumn{6}{|c|}{ Epocas de aplicaçâo } \\
\hline & \multicolumn{2}{|c|}{ Plantio } & \multicolumn{2}{|c|}{ Perfilhamento } & \multicolumn{2}{|c|}{ Emborrachamento } \\
\hline & $\mathrm{kgN} / \mathrm{ha}$ & forma & $\mathrm{kgN} / \mathrm{ha}$ & forma & $\mathrm{kgN} / \mathrm{ha}$ & forma \\
\hline 1 & 0 & - & 0 & - & 0 & - \\
\hline 2 & 60 & sólida & 0 & - & 0 & - \\
\hline 3 & 20 & $"$ & 20 & sólida & 20 & sólida \\
\hline 4 & 30 & $"$ & 30 & sólida & 0 & - \\
\hline 5 & 30 & $"$ & 0 & - & 30 & sólida \\
\hline 6 & 90 & $"$ & 0 & - & 0 & - \\
\hline 7 & 30 & $"$ & 30 & sólida & 30 & sólida \\
\hline 8 & 45 & $"$ & 45 & sólida & 0 & - \\
\hline 9 & 45 & $"$ & 0 & - & 45 & sólida \\
\hline 10 & 20 & $"$ & 20 & liquida & 20 & liquida \\
\hline 11 & 30 & $"$ & 30 & líquida & 0 & - \\
\hline 12 & 30 & $"$ & 0 & - & 30 & líquida \\
\hline 13 & 30 & $"$ & 30 & líquida & 30 & líquida \\
\hline 14 & 45 & $"$ & 45 & líquida & 0 & - \\
\hline 15 & 45 & $"$ & 0 & - & 45 & líquida \\
\hline
\end{tabular}

Nas aplicações em aspersão foi adicionado espalhante adesivo, Triton, à razão de $0,1 \mathrm{ml} / 1$. Todas as parcelas receberam uma adubação com $120 \mathrm{~kg} / \mathrm{ha}$ de $\mathrm{P}_{2} \mathrm{O}_{5}$ e $60 \mathrm{~kg} / \mathrm{ha}$ de ${ }_{2} 0$, mas formas de superfosfato simples e cloreto de potássio.

A área da parcela foi de $6 \mathrm{~m}^{2}(2 \times 3 \mathrm{~m})$, sendo a área útil de $2 \mathrm{~m}^{2}(1 \times 2 \mathrm{~m})$, com espaçamento de $20 \mathrm{~cm}$ entre fileiras com uma densidade de plantio de 400 sementes $/ \mathrm{m}^{2}$.

Os fertilizantes utilizados foram: uréia com $45 \% \mathrm{~N}$, superfosfato simples com $21 \%$ de $\mathrm{P}_{2} 0_{5}$ e cloreto de potássio com $60 \%$ de $\mathrm{K}_{2} 0$.

A variedade utilizada foi a IAS-51, fornecida pela Secretaria de Agricultura do Estado do Paraná. Esta variedade está no grupo daquelas que produzem farinhas médias, conforme PAPE et al. 1971. 


\section{Condução do ensaio}

A semeadura foi efetuada a 22.06 .71 e os parcelamentos de uréia no perfilhamento e emborrachamento se deram respectivamente aos 39 e 80 dias após o plantio. Para a aspersão da solução de uréia usou-se - pulverizador LVA, LVC, a pilhas. No tratamento das parcelas por pulverização foliar, a contaminação das parcelas vizinhas foi evitada por paredes de $1,5 \mathrm{~m}$ de altura, em plástico, colocadas ao redor da parcela a ser tratada. A colheita foi realizada aos 141 dias e a debulha processada em trilhadeira de parcela.

Trblho de Laboratório

Análise de produção

A produção de palha e grão foi determinada. A umidade, peso de 1.000 grãos e peso de hectolitro foi determinada segundo recomendações oficiais adotadas pelo Ministério da Agricultura ${ }^{(*)}$.

Análise química dos grãos

As amostras de grãos devidamente secas, foram moidas, em moinho "Wiley" e as determinações de nitrogênio feitas pelo método de Kjeldahl. Foram preparados extratos nitroperclórico para as determinações de fósforo e potássio. O fósforo foi determinado colorimetricamente pelo método do vanadomolibdato de amonio (LOTT et al., 1956), no fotocolorímetro KLETT SUMMERSON. O potássio foi determinado por foto metria de chama, no fotômetro de absorção atômica EEL.

Para as análises de aminoácidos, as amostras dos grãos foram trituradas em almofariz, tratadas com acetona para extrir gorduras e o extrato seco separado em funil de "Buchner". Trinta miligramas do pó resultante, foram tomados em $10 \mathrm{ml}$ de $\mathrm{HC} 16 \mathrm{~N}$, em tubos fechados e levados à estufa a $110^{\circ} \mathrm{C}$. Decorridas 24 horas, filtrados e lavados com água. O filtrado foi levado a um evaporador rotatório, à vácuo, até compieta eliminaçào do $\mathrm{HC} 1$. As amostras foram retomadas em $5 \mathrm{ml}$ de uma solução tampão de citrato de sódio, $\mathrm{pH} \mathrm{2,2,} \mathrm{e,} \mathrm{analisadas,}$ segundo MOORE et al. (1958), no Amino Acid Analyser 120-C da Beckman. Para a determinação do Triptofano, $500 \mathrm{mg}$ da farinha desengordurada obtida da forma descrita foram tratadas com $1 \mathrm{ml} \mathrm{d}$ mistura (70 ml etanol + 0,6 ml 2-mercaptana, completando a $100 \mathrm{ml}$ com água), agitando por 13 " hora. Adicionou-se mais $5 \mathrm{ml}$ de $\mathrm{NaOH} 0,5 \%$ e depois de nova agitação por 1 hora, centrifugou-se guardando o sobrenadante em temperatura ambiente. As determinações foram feitas segundo o método de GAITONDE e DOVEY (1970).

* Regras para Análise de Sementes - Ministério da Agricultura - 1967. 
As determinações do teor e qualidade do gluten, foram feitas segundo o método de BERLINER e KOOPMAN, descrito por KENT-JONES e AMOS (1967).

\section{RESULTADOS E DISCUSSÃO}

Produção, Peso de 1.000 grãos e peso volumétrico

Os resultados referntes a produção, peso de 1.000 grãos e peso volumétrico são apresentados no Quadro 3.

QUADRO 3 - Produção de grãos de trigo em $\mathrm{kg} / \mathrm{ha}$, peso de 1.000 grãos em gramas e peso volumétrico (hectolitro) $\mathrm{em} \mathrm{Kg}$

\begin{tabular}{|c|c|c|c|c|c|}
\hline Tratamento & $\begin{array}{l}\text { Produçã̃o } \\
\mathrm{kg} / \text { tha }\end{array}$ & $\begin{array}{c}\text { Peso de } \\
1.000 \\
\text { grãos (g) }\end{array}$ & $\begin{array}{l}\text { Peso de } \\
\text { hectoli- } \\
\text { tro (kg) }\end{array}$ & $\begin{array}{c}\text { Proteina } \\
(\%)\end{array}$ & $\begin{array}{c}\text { Arc sen } \\
\vee \%\end{array}$ \\
\hline 1 & 1153 & 33.1 & 80,5 & 11,08 & 19,43 \\
\hline 2 & 2017 & 40,4 & 81.3 & 11,90 & 20,18 \\
\hline 3 & 1714 & 37,5 & 81,0 & 13,30 & 21,38 \\
\hline 4 & 1816 & 40.0 & 80.7 & 12.09 & 20,35 \\
\hline 5 & 1729 & 39,6 & 81,0 & 12,45 & 20,66 \\
\hline 6 & 1804 & 38,1 & 79,4 & 12,47 & 20,68 \\
\hline 7 & 1693 & 38,8 & 80,8 & 13,38 & 21.47 \\
\hline 8 & 1890 & 39,7 & 81,1 & 12,89 & 21,04 \\
\hline 9 & 1757 & 38,6 & 81,0 & 13,92 & 21,89 \\
\hline 10 & 1767 & 38,3 & 81,0 & 12,17 & 20,44 \\
\hline 11 & 1810 & 38,9 & 80,3 & 11,83 & 20,13 \\
\hline 12 & 18.96 & 40,4 & 81,6 & 12,17 & 20,41 \\
\hline 13 & 2046 & 39,8 & 81,5 & 13,34 & 21,40 \\
\hline 14 & 1876 & 40,7 & 81,2 & 13,41 & 21,47 \\
\hline 15 & 1949 & 39,7 & 80,4 & 12,98 & 21,13 \\
\hline DMS (Tukey 1\%) & 744 & 4,9 & 2,7 & & 1,83 \\
\hline (Tukey 5\%) & 5.5 & 1,2 & 2,4 & & 1,57 \\
\hline CX\% & 12,09 & 4,21 & 1,15 & & 2,10 \\
\hline
\end{tabular}

O esquema de análise de variância adotado para a apreciação dos dados do Quadro 3, e os valores encontrados pelo teste $F$, constam do Quadro 4. 
QUADRO 4 - Esquema da análise de variância, valor e significância de $\mathrm{F}$, para produção, peso de 1.000 grãos e fósforo, potássio e proteína no grão de trigo.

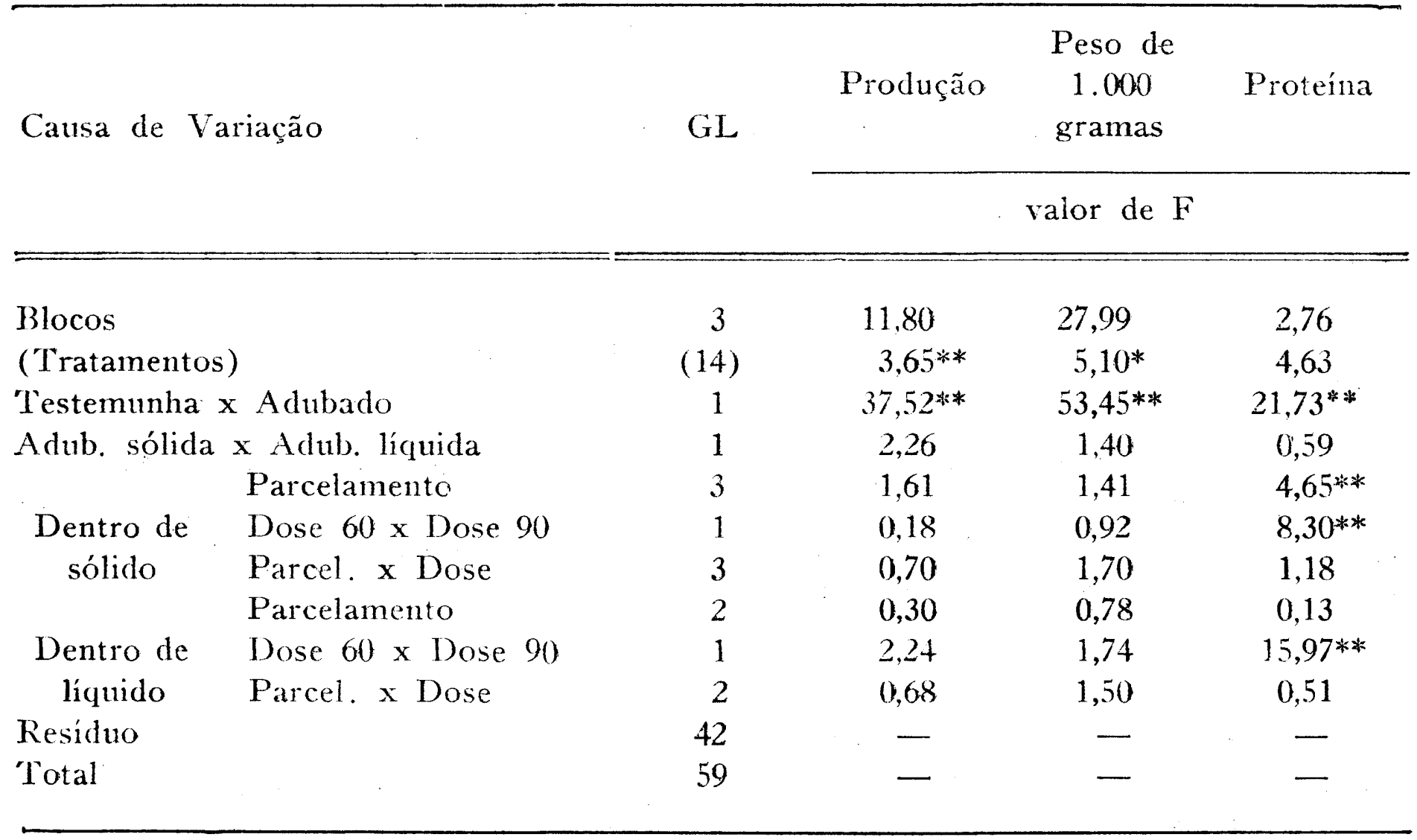

Conforme se observa no Quadro 3, houve aumento de produção para todos os tratamentos que receberam adubação nitrogenada em relação à testemunha e sómente para o tratamento 7 este aumento não foi significativo. Saliente-se que no presente trabalho, todos os tratamentos resultaram em produções acima da média do país para o mesmo ano, sendo que no Paraná, esta média foi de $868 \mathrm{~kg} /$ ha (ANUÁRIO ESTATISTICO DO TRIGO, safra 1970/1971).

Não foram registradas diferenças significativas quanto ao parcelamento ou época de aplícação, o mesmo acontecendo quando se elevou a dose de $\mathrm{N}$ de 60 para $90 \mathrm{~kg}$ de $\mathrm{N} / \mathrm{ha}$.

Quando se considerou a forma de aplicação, quer seja no solo ou em pulverização foliar, os resultados também foram semelhantes, ccncordando com THORNE (1955), GARDNER (1955) e MATHUR et la. (1969) .

Apesar de se terem obtido produções ao redor do dobro da méclia brasileira, podem-se considerá-las um tanto insatisfatórias quando comparadas com as produções obtidas em lavouras na mesma região tricíicola e principalmente com as obtidas em alguns países como México, India e Paquistão, que são üa ordem de 3.000 e $4.000 \mathrm{~kg} / \mathrm{ha}$, respectivamente. 
Uma das razões que podem ter limitado a produção de trigo neste experimento teria sido, talvez, a relativa pobreza do solo, que apresentava teores de médio a baixo de nutrientes, conforme se deprende da análise química do solo. Outra razão provável seria um possivel deficit de água para a cultura, na ocasião do perfilhamento, conforme se verifica no Quadro 1.

$O$ peso de 1.000 grãos foi afetado significativamente em favor dos tratamentos que recebem adubação nitrogenada. Consideradas as variações destes tratamentos não se obteve diferenças significativas entre eles.

Quanto ao peso do hectolitro não se constatou diferenças entre os tratamentos.

Se houve aumento significativo no peso dos grãos para todos os tratamentos que receberam uréia e permaneceu inalterado o peso de hectolitro, pode-se inferir que a adubação nitrogenada provocou um aumento no tamanho dos grãos.

Teor de proteína

Os resultados obtidos para o teor de proteína, nos grãos do trigo, são apresentados no Quadro 3. Para a obtenção daqueles dados, multiplicaram-se os resultados obtidos par a concentração de $\mathrm{N}$ por fator 5,7 segundo BAILEY, (1944).

Conforme se observa, um aumento no teor de proteína pela aplicação de uréia deveu-se principalmente às doses de $90 \mathrm{kgN} / \mathrm{ha}$ sendo que, quando se considerou a forma de aplicação, os resultados não foram diferentes estatísticamente.

O aumento máximo, no teor de proteína, foi de aproximadamer.e $10,0 \%$ em relação ao valor encontrado para a testemunha.

Analisando os resultados, sómente para os tratamentos que receberam ureia na forma sỏlida, observou-se diferenças significativas em favor do maior número de parcelamento, e, ainda, em favor das aplicaçöes mais tardias, conforme mostram os dados transformados em ar sen v\% proteína:

Alguns dados procurando mostrar a influência exercida pela adubação nitrogenada sobre caracteres qualitativos dos grãos de trigo são apresentados no Quadro 5.

Observando os resultados apresentados, nota-se que as produções de grão e proteina do grão, transformadas em $\mathrm{kg} / \mathrm{ha}$, foram sempre maiores para os tratamentos que receberam adubação nitrogenada, o 
mesmo acontecendo com lisina, iso-leucina e triptofano apresentados na mesma unidade. Quando, porém, se confrontam gramas de aminoácidos por 100 gramas de proteína, observaram-se, que os dados obtidos. para lisina são sempre menores para os tratamentos adubados com nitrogênio. Para iso-leucina os dados apresntam-se inconsistentes e permanecem praticamente constantes para o triptofano.

\begin{tabular}{ll}
\hline Aplicação no plantio & 20,43 \\
Aplicação no plantio e perfilhamento & 20,70 \\
Aplicação no plantio e emborrachamento & 21,28 \\
Aplicação nas três épocas & 21,43 \\
\hline DMS (Tukey 5\%) & 0,82 \\
\hline
\end{tabular}

Segundo KAUL (1973), os primeiros aminoácidos limitantes em grãos de trigo são lisina e iso-leucina respectivamente. A inclusão dos dados refernetes ao triptofano, prende-se ao fato de KAUL (1973), para os cereais em geral, o terceiro aminoácido a figurar na lista dos primeiros limitantes é o triptofano.

Comparando-se os dados obtidos no presente trabalho, 3,03\% para lisina e $3,64 \%$ para iso-leucina, na proteína do tratamento que não recebeu adubação nitrogenada, com os encontrados como valor médio, para trigo, ou seja, 2,7\% par lisina e 3,6\% par iso-leucina, (FAO, 1957), verifica-se ter havido um decréscimo na qualidade protética dos tratamentos que receberam adubação nitrogenada, revelado pelos teores de lesina.

Para teor e qualidade do gluten, observa-s e que, nquanto a aplicação d uréia favoreceu o teor de gluten, os dados obtidos para a qualidade permanecem praticamente constantes ,devendo a sua variação estar condicionada à carga genética de variedade. Isto vem encontrar apoio nos resultados obtidos por VLASYUK e RUDENKO (1969).

Os valores usados para classificar a qualidade da farinha de trigo quanto ao teor de gluten são: maior que 30\%, teor elevado; $25 \%$ teor médio e menos do que $20 \%$ teor baixo. Para os resultados usados ro presente trabalho observa-se que a farinha do tratamento testemunha apresentou um teor de $22,70 \%$ de gluten e se enquadra numa faixa abaixo do teor médio, enquanto que, os tratamentos que receberam adubação nitrogenada estão todos acima do teor médio, e, nove dentre os 14 tratamentos apresentam farinhas com elevado teor de gluten.

Quanto à qualidade do gluten, parece não ter havido variação em função dos tratamentos, concordando com COIC (1957), o qual afirma que a qualidade do gluten é dependente da variedade. 


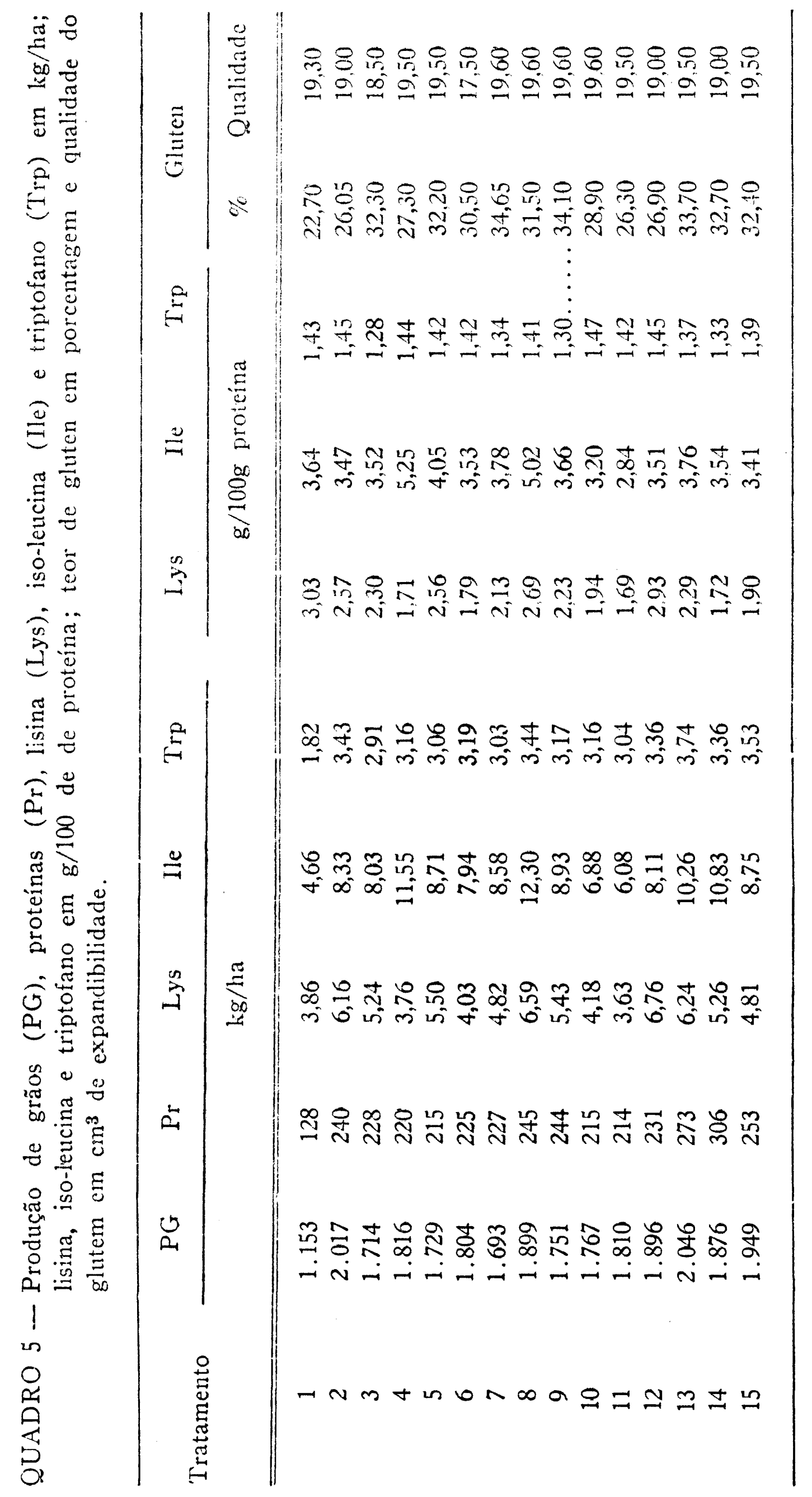




\section{CONCLUSŌES}

Para o ano agrícola, local e variedade utilizad no experimento, podemos concluir que:

- a adubação nitrogenada, aumentou a produção e o tamanho dos grãos de trigo, independentemente da época, dose ou forma de aplicação.

- o parcelamento e aplicação mais tardias, favoreceram o aumento do teor de proteína principalmente para a dose de $90 \mathrm{kgN} / \mathrm{ha}$, independentemente da forma de aplicação.

- a adubação nitrogenada parec influir na diminuição da qualidade das proteínas e no aumento do teor de gluten, sem influenciar na qualidade deste último.

\section{SUMMARY}

EFFECT OF UREA APPLIED IN SOIL AND BY FOLIAR SPRAYNG ON YELD AND QUALITY OF WHEAT (Triticum aestivum, L..)

The objective of the present work was to study the effect of nitrogen fertilizers on wheat (Triticum asstivum L.), under field conditions.

The experiments were carried out in 1971 at the Vila Velha Experimental Station of the Agricultural Office of the State of Paraná, situated in the urban district of Ponta Grossa-PR.

Treatments with 60 and $90 \mathrm{Kg} \mathrm{N} / \mathrm{ha}$ and withont nitrogen were compared, in the presence of $120 \mathrm{Kg} \mathrm{P}_{2} \mathrm{O}_{5} / \mathrm{ha}$, in the form of superphosphate and $60 \mathrm{Kg} \mathrm{K}, \mathrm{O} / \mathrm{ha}$ in the form of potassium chloride.

The nitrogen fertilizer used was urea, with $45 \%$ of nitrogen, applied in solid form in the planting furrow and as a top dressing, and in both the solid form and as a $2 \%$ solution sprayed onto the leaves at the tillering and booting stages.

The results obtained showed that an increase in grain production occurred when nitrogen was applied, although there was no significant difference between time of application. split application, form and quantity of nitrogen.

Production of protein, as measured by total nitrogen, was significantly higher for doses of $90 \mathrm{kgN} / \mathrm{ha}$. As far as the use of fertilizer in the solid form is concerned best results were obtained with split application or with applications at later stages. This was not true, however, when application was made by sprayng the leaves. The forms of application were equivalent.

Nitrogen application decreases the level of lysine and increases the gluten content content of the grain, when compared with the control. 


\section{LITERATURA CITADA}

ANUÁRIO ESTATISTICO DO TRIGO, safra 1970/1971. Ministério da Agricultura, CCLF - Porto Alegre - RS.

BAlLEY, C.H., 1944. The constituinte of wheat and wheat products. ACS monograph séries. Reinhold publising corporation, New York.

BOURLAUG, N.E., 1969. Mejoramento del trigo: Su impacto en el abastecimiento mundial de alimentos - Centro Internacional de Mejoramiento de Maiz e Trigo - México.

CATANI, R.A., J.R. GALLO e H. GARGANTINI, 1955. Amostragem do solo, métodos de análises, interpretação e indicações para fins de fertilidade. Boletim n. ${ }^{\circ}$ 69. Inst. Agron. Campinas.

COIC, Y., 1957. Influence de la nutrition et de la fertilisation azotée du blé sur la qualité du pain. Bulletin des Anciens élèves de l'Ecole Française de Meurenic. 157:28-34.

F.A.O., 1957. F.A.O. Nutr. Studies (16). Nações Unidas - Organização de Nutrição e Alimentação.

FINNEY, K.F., J.W. MEYER, F.W SMITH e H.C. FRYER, 1957. Effect of foliar spraying of Pawnee wheat with urea solutins on yield, protein content and protein quality. Agr. J. 49:341-347.

GAITONDE, M.K., DOVEY, T., 1970. A rapid and irect method for the quantitative determination of triptophan in the intact protein. Biochem. J. 117;907.

GARDNER, H.W., 1955. Foliar application of nitrogen to winter what. Agricultura, 62: 267-269.

GLORIA, N.A. de, R.A. CATANI e T. MATUO, 1965. O bétodo de EDTA na determinação de cálcio e magnésio trocável do solo. Rev. Agric. Piracicaba 40: 47-74.

HAMID, A., 1972. Efficiency of $\mathrm{N}$ uptake by wheat, as affected by time and rate of application, using $\mathrm{N}^{15}$-labelled ammonium sulphate and sodium nitrate. Plant and soil. 37:389-394.

HERA, C., 1970. Soil and fertilizer nitrogen in specific plant components, with emphasis on small grains. Environmental influences and fertilizer management. Nitrogen-15 in Soil-Plant Studies. Proceeding of a Symposium. IAEAïFAO - 1971.

HUCKLESBY, D.P., C.M. BROWN, S.E. HOWELL e R.H. HAGEMAN, 1971. Late spring application of nitrogen for efficient utilization and enhanced production of grain and grain protein of wheat. Agron. Jour. 63:274-276.

HUNTER, A.S., C.J. GERARD, H.M. WADDOUPS, W.E. HALL, H.E. CUSHMAN e L.A.A. ALBAN, 1958. The efect of nitrogen fertilizer on the relationships between increases in yelds and protein content of Pastry-typ? wheats. Agron. J. 50: 311-314.

JACKSON, M.L., 1958. Soil Chemical Analysis. Englewood Cliffs, N.J. Prentice Hall Inc. 498 pp.

KALCKMANN, R.E., 1965. Contribuição ao estudo da adubação e das variedades de trigo, nos solos ácidos do Rio Grande do Sul. Tese não publicada. E.A.V.U.F.P. Curitiba-PR.

KAUL, D.R., 1973. Mutation breeding and crop protein improvement. Nuclear Technques for Seed Protein Improvement. IAEA. Vienna.

KENT-JONES, D.W. e A.J. AMOS, 1967. Modern cereal chcmistry-sixth edition - Food Trade Press Ltd. p. 156. London.

LITTLER, J.W., 1962. Effect of time and rate of application of urea to wheat. Queensland J. of Agric. Sci. 19:323-344.

LOTT, W.L., J.P. NERY, J.R. GALLO e J.C. MEDCALF, 1956. A técnica de análise foliar aplicada ao cafeeiro. Ibec Research Institute Bol. n. 9. 
MATHUR, B.S., P.S. BHATN.GAR e S. SINGH, 1969. Foliar and soil applications of nitrogen to wheat. Trop. Agric. Trin. 46:255-259.

McCALLA, A.G., 1933. The effect of nitrogen nutrition on the protein and non protein nitrogen of wheat. Con. Jour. Res. 9 542-570.

MCNEAL, F.H. e D.J. DAVIS, 1954. Effect of nitrogen fertilization on yeld, culm number and protein content of certain of certain spring wheat varieties - Agron. J. $46(8): 375-378$.

MINISTERIO DA AGRICULTURA, 1957. Regras para análise de semente. $120 \mathrm{pg}$.

MOORE, S., D.H. PACKMAN e W.H. STEIN, 1958. Cromatography of amino-acils on sulfonated polysturene resins: an improved system. Anal Chem. 30, 118.5.

MORRIS, H.D. e J.E. JACKSON, 1959. Source and time of application of nitrogen for rye forage. Soil Sci. Soc. Amer. Proc. 23:305-307.

NEPTUNE, A.M.L. e J.F. PATELLA, 1970. Efficiency of fertilizer nitrogen sources applied to wheat on influenced by times and rates of nitrogen applications. Final report - Anual Meeting-Rabat, Marrocos, Joint FAO/IAEA-CENA/ESAIQ-USP.

NERSON, H., e Z. KARCHI, 1972. A comparative study of soil versus foliar application of ammonium nitrate to wheat under different moisture regimes - 1srael J. Agric. Res. 22(3): 171-177.

PAN, IV., 1969. Trigo no norte do a Praná - IPEAME - Circular n. ${ }^{0} 1$. Colombo-PR.

PATELLA, J.F., 1969. Resultados obtidos com a cultura do trigo no Setor de Solos do IPEAS em 1969. Mimeografado, $11 \mathrm{pg}$. Pelotas-RS.

PUENTE, F., E.S. de COES e R.J. LAIRD, 1958. R1 tiempo de applicacion del nitrogeno afecta al rendimiento y calidad del trigo. Agric. Tec. en México. 1957-1957. 5:33-34.

PAPE. G., J.C. ORLANDO, J.E. CAMPOS e M. LIMA, 1971. Estudo tecnológico dis principais variedades de trigo $\mathrm{cm}$ cultivo e linhagens em experimentação avançada do Ministério da Agricultura. Trabalho apresentado na IIIa. Reunião Anual Conjunta de Trigo, Curitiba.

RAMON, F.G. y R.J. LAIRD, 1958. Humedad del suelo y fertilizacion nitrogenada. Su ralacion con el contenido de proteinas en el trigo. 1957-1958 - 5:31-32.

RAMOS, M.G., 1970. Resultados de adubação. Resumo apresentado à Reunião) Nacional de Trigo. Porto Alegre-RS. (nimeografado).

RINKIN, W.H., 1946. Eifect of nitrogen suppled at various stages of growth on the levelopment of wheat plant. Soil Sci. Soc. Aner. Proc. 11:384-387.

SAUAPHAL, M.N. e N.B. DAS, 1965. Effect of spraymg wea no winter wheat (Triticum aestivum). Agr. J. 58(2):137-141.

SRIVASTAVA, K.N., V. PRAKASIH, R. DE e M.S. NAIK, 1970. Improvement of the quality of proteins of "S277" wheat by nitrogen fertilization under rain-fed conditions - Indian J. Agric. Sci. 41(3): 202-205.

THORNE, G, 1955. Nutrient uptake from leaf sprays by crops. Field crops abstracts. 8: $147-151$.

VILLA NOVA. N.A., K. REICHARDT e A.A. ORTOLANI, 1968. Principais métorlos climáticos de estimativa e de média da perda de água de superfícies naturais. ESALQ-USP - Piracicaba-SP. (Mimeografado).

VLASYUK, P.A. e G.S. RUDENKO, 1969. Industrial breadbaking properties of wintes wheat grain at varions fertilization levels. Soviet Soils Scicnce. 3:321-325.

WAHHAB, A. e I. HUSSAIN, 1957. Effect of nitrogen on growth, quality, and yield of irrigated wheat in west Pakistan. Agron. J. 49:116-119.

WITTWER, S.H. e F.G. TEUBNER, 1959. Foliar absortion of mineral nutrientes. Amual Rev. of Plant Phys. 10:13-32. 
